\title{
Thermal Vacancies in High-Entropy Alloys
}

\author{
Taichi Abe*
}

Research Center for Structural Materials, National Institute for Materials Science, Tsukuba 305-0047, Japan

The thermodynamic description of vacancies in binary alloys was expanded to high-entropy alloys (HEAs) within the framework of the CALPHAD method and was applied to estimate the vacancy fraction and the vacancy formation enthalpy in the HEA CoCrFeMnNi. Using the average value of the vacancy formation enthalpy in the pure elements and the excess Gibbs energies in the binary subsystems, the formation enthalpy in the HEA was found to be $1.7 \mathrm{eV}$. This value is in good agreement with the experimental value of $1.72 \mathrm{eV}$ determined by the positron annihilation technique. This result suggests that the sluggish diffusion cannot be explained from the viewpoint of vacancy formation enthalpy. [doi:10.2320/matertrans.MT-MK2019008]

(Received January 14, 2020; Accepted January 22, 2020; Published March 2, 2020)

Keywords: binding energy, monovacancy, ideal solution, vacancy formation enthalpy

\section{Introduction}

The existence of the sluggish diffusion in high-entropy alloys (HEAs) has been reported by $\mathrm{Yeh}^{1)}$ and by other researchers. $^{2-4)}$ They have found slow kinetic behaviors in HEAs comparing to those in pure or dilute alloys. Tsai and $\mathrm{Yeh}^{2)}$ explained the sluggish diffusion on the basis of an atom trapping mechanism at low energy sites in the crystal, which is originated from a variety of local atomic configurations in HEAs. Since the sluggish diffusion is categorized as one of four core effects of $\mathrm{HEAs},{ }^{2)}$ it has attracted intensive interest. In recent years, however, this mechanism has become controversial as many research groups who have investigated the sluggish diffusion have concluded that it may not be related to configurational effects. ${ }^{5-8)}$

If sluggish diffusion occurs, it should be reflected in the diffusion coefficients. From the thermodynamic point of view, diffusion coefficient, $D$, is given by

$$
D=D_{0} \exp \left(-\frac{G^{\mathrm{M}}+G^{\mathrm{F}}}{R T}\right)
$$

where $D_{0}, G^{\mathrm{M}}$, and $G^{\mathrm{F}}$ are a prefactor, the Gibbs energy of vacancy migration, and the Gibbs energy of vacancy formation, respectively. If the sluggish diffusion is true, the difference between HEAs and conventional alloys should be found in these properties. Since the late $\left.1960 \mathrm{~s},{ }^{9}\right)$ the properties of vacancies have been intensively investigated because of their practical importance in precipitations and diffusion kinetics. In the CALPHAD (CALculations of PHAse Diagrams)-type thermodynamic analysis, ${ }^{10)}$ descriptions of crystal defects have been formulated for monovacancies, ${ }^{11-14)}$ divacancies, ${ }^{15)}$ and solute-vacancy pairs $^{15)}$ in binary alloys. For multicomponent systems, however, descriptions of vacancies and the vacancy complex have not yet been formulated within the framework of the CALPHAD method.

In the present work, therefore, it is aimed that the descriptions of the vacancy in unary and binary systems are expanded to multi-component systems and are applied for the estimation of the vacancy formation enthalpy and the

*Corresponding author, E-mail: abe.taichi@nims.go.jp vacancy fraction in HEAs to examine the high entropy effect on the vacancy formation.

\section{Vacancies in Binary Solid Solutions}

The Gibbs energy of a binary solid solution with a vacancy can be given by the regular solution model. The physical meanings of the parameters in the Gibbs energy equation have already been discussed in previous works. ${ }^{11-15)}$ The obtained results are briefly explained in this section for further discussion in subsequent sections. The Gibbs energy of an A-B binary solution with a vacancy, $G_{\mathrm{m}}^{\mathrm{A}-\mathrm{B}-\mathrm{Va}}$, is given by

$$
G_{\mathrm{m}}^{\mathrm{A}-\mathrm{B}-\mathrm{Va}}=\frac{1}{1-y_{\mathrm{Va}}}\left\{\begin{array}{l}
\sum_{i} y_{i} G_{\mathrm{m}}^{i}+R T \sum_{i} y_{i} \ln y_{i} \\
+\sum_{i} \sum_{j} \sum_{l} y_{i} y_{j}\left(y_{i}-y_{j}\right)^{l} L_{i, j}^{(l)} \\
+y_{\mathrm{A}} y_{\mathrm{B}} y_{\mathrm{Va}}\left(y_{\mathrm{A}}{ }^{0} L_{\mathrm{A}, \mathrm{B}, \mathrm{Va}}\right. \\
\left.+y_{\mathrm{B}}{ }^{1} L_{\mathrm{A}, \mathrm{B}, \mathrm{Va}}+y_{\mathrm{Va}}{ }^{2} L_{\mathrm{A}, \mathrm{B}, \mathrm{Va}}\right)
\end{array}\right\},
$$

where Va denotes a vacancy, $G_{\mathrm{m}}^{i}$ is the Gibbs energy of pure component $i, y_{i}$ is the mole fraction of $i, T$ is the temperature in kelvin and $R$ is the gas constant. $L_{i, j}^{(l)}$ is $l$-th term of the Redlich-Kister $(\mathrm{R}-\mathrm{K})$ polynomial between components $i$ and $j\left(i, j=\mathrm{A}, \mathrm{B}\right.$, and Va). ${ }^{0} L_{\mathrm{A}, \mathrm{B}, \mathrm{Va}},{ }^{1} L_{\mathrm{A}, \mathrm{B}, \mathrm{Va}}$, and ${ }^{2} L_{\mathrm{A}, \mathrm{B}, \mathrm{Va}}$ are the ternary interaction parameters among $\mathrm{A}$, $\mathrm{B}$, and Va. Under constant temperature and pressure, the mole fraction of the vacancy in equilibrium is given at the minimum of the Gibbs energy with respect to the mole fraction of the vacancy. For a pure-element A with vacancies, eq. (2) can be simply given by applying $y_{\mathrm{A}}=1, y_{\mathrm{B}}=0$, and $y_{\mathrm{Va}} \ll 1$. Thus, the vacancy fraction at equilibrium, $d G_{\mathrm{m}}^{\mathrm{A}-\mathrm{B}-\mathrm{Va}} / d y_{\mathrm{Va}}=0$, is

$$
y_{\mathrm{Va}}=\exp \left(-\frac{G_{\mathrm{m}}^{\mathrm{Va}}+L_{\mathrm{A}, \mathrm{Va}}^{(0)}}{R T}\right) .
$$

The 0-th $\mathrm{R}-\mathrm{K}$ parameter, $L_{\mathrm{A}, \mathrm{Va}}^{(0)}$, in eq. (3) is related to the vacancy formation Gibbs energy and is given by

$$
L_{\mathrm{A}, \mathrm{Va}}^{(0)}={ }^{f} H_{\mathrm{A}}^{\mathrm{Va}}-{ }^{f} S_{\mathrm{A}}^{\mathrm{Va}} T-G_{\mathrm{m}}^{\mathrm{Va}},
$$

where ${ }^{f} H_{\mathrm{A}}^{\mathrm{Va}}$, and ${ }^{f} S_{\mathrm{A}}^{\mathrm{Va}}$ are the vacancy formation enthalpy and entropy, respectively. ${ }^{14)}$ 
The effect of vacancy-solute atom pair formation can be introduced based on a thermodynamic model proposed by Lomer ${ }^{16)}$ for a solution with a small fraction of B. According to Ref. 15), the ternary interaction parameters ${ }^{0} L_{\mathrm{A}, \mathrm{B}, \mathrm{Va}}$ and ${ }^{1} L_{\mathrm{A}, \mathrm{B}, \mathrm{Va}}$ in eq. (2) are related to the binding energy between the vacancy-solute pair given by

$$
\begin{aligned}
& { }^{0} L_{\mathrm{A}, \mathrm{B}, \mathrm{Va}}=\frac{z}{y_{\mathrm{A}}^{2}} H_{\mathrm{A}}^{\mathrm{B}-\mathrm{Va} \_ \text {Bind }} \simeq z H_{\mathrm{A}}^{\mathrm{B}-\mathrm{Va} \_ \text {Bind }}, \\
& { }^{1} L_{\mathrm{A}, \mathrm{B}, \mathrm{Va}} \simeq z H_{\mathrm{B}}^{\mathrm{A}-\mathrm{Va} \_ \text {Bind }},
\end{aligned}
$$

where $z$ is the coordination number $(z=12$ for the FCC and HCP lattices and 8 for the $\mathrm{BCC}$ lattice). $H_{\mathrm{A}}^{\mathrm{B}-\mathrm{Va}-\mathrm{Bind}}$ and $H_{\mathrm{B}}^{\mathrm{A}-\mathrm{Va}-\mathrm{Bind}}$ are the $\mathrm{B}-\mathrm{Va}$ binding enthalpy in the A-rich solid solution and the A-Va binding enthalpy in the B-rich solid solution, respectively.

\section{Gibbs Energy of HEAs with a Vacancy}

In this section, the Gibbs energy of the A-B binary solution given by eq. (2) is expanded to HEAs. For a multicomponent substitutional solution, the phase with a single sublattice is defined as

$$
(\mathrm{A}, \mathrm{B}, \mathrm{C}, \mathrm{D}, \mathrm{E}, \mathrm{Va}, \ldots)_{p},
$$

where $p$ is the number of moles of the substitutional site. The total amount of atoms is unity. The Gibbs energy of this substitutional solution phase for one mole of atoms, $G_{\mathrm{m}}^{\mathrm{HEA}-\mathrm{Va}}$, is given by

$$
G_{\mathrm{m}}^{\mathrm{HEA}-\mathrm{Va}}=\frac{1}{1-y_{\mathrm{Va}}}\left\{\begin{array}{l}
\sum_{i} y_{i} G_{\mathrm{m}}^{i}+R T \sum_{i} y_{i} \ln y_{i} \\
+\sum_{i} \sum_{j} \sum_{l} y_{i} y_{j}\left(y_{i}-y_{j}\right)^{l} L_{i, j}^{(l)} \\
+\sum_{i} \sum_{j} y_{i} y_{j} y_{k}\left(y_{i}{ }^{0} L_{i, j, k}\right. \\
\left.+y_{j}{ }^{1} L_{i, j, k}+y_{k}{ }^{2} L_{i, j, k}\right)
\end{array}\right\} \text {, }
$$

where $L_{i, j}^{(l)}$ is the interaction parameter between components $i$ and $j$. The prefix $l$ denotes the $l$-th term of the R-K polynomial. ${ }^{0} L_{i, j, k},{ }^{1} L_{i, j, k}$, and ${ }^{2} L_{i, j, k}$, are the ternary interaction parameters among $i, j$, and $k$. Under constant temperature and pressure, the mole fraction of the vacancy at equilibrium is given by the minimum of the derivative with respect to the mole fraction of the vacancy $\left(d G_{\mathrm{m}}^{\mathrm{HEA}-\mathrm{Va}} / d y_{\mathrm{Va}}=0\right)$. Although the ternary interaction parameters include the mixing among elements without vacancies, they were omitted in the present work because such mixing may be sufficiently small in the HEAs. Since the highest vacancy fraction is obtained at the melting point and is about $10^{-3}$, assuming that it is the dilute solution where $y_{\mathrm{Va}} \ll 1$, the first derivative of the Gibbs energy is

$$
\begin{aligned}
\frac{d G_{\mathrm{m}}^{\mathrm{HEA}-\mathrm{Va}}}{d y_{\mathrm{Va}}}= & G_{\mathrm{m}}^{\mathrm{Va}}+R T \ln y_{\mathrm{Va}} \\
& -\sum_{i} \sum_{j} \sum_{l}(1+l) y_{i} y_{j}\left(y_{i}-y_{j}\right)^{l} L_{i, j}^{(l)} \\
& +\sum_{i} \sum_{l} y_{i}^{l+1} L_{i, \mathrm{Va}}^{(l)} \\
& +\sum_{i} \sum_{j} y_{i} y_{j}\left(y_{i}{ }^{0} L_{i, j, \mathrm{Va}}+y_{j}{ }^{1} L_{i, j, \mathrm{Va}}\right. \\
& \left.+2 y_{\mathrm{Va}}{ }^{2} L_{i, j, \mathrm{Va}}\right) .
\end{aligned}
$$

At equilibrium, the mole fraction of vacancies is

$$
y_{\mathrm{Va}}=\exp \left[\begin{array}{c}
G_{\mathrm{m}}^{\mathrm{Va}}-\sum_{i} \sum_{j} \sum_{l}(1+l) y_{i} y_{j}\left(y_{i}-y_{j}\right)^{l} L_{i, j}^{(l)} \\
+\sum_{i} \sum_{l} y_{i}^{l+1} L_{i, \mathrm{Va}}^{(l)} \\
+\sum_{i} \sum_{j} y_{i} y_{j}\left(y_{i}{ }^{0} L_{i, j, \mathrm{Va}}+y_{j}{ }^{1} L_{i, j, \mathrm{Va}}\right) \\
R T
\end{array}\right] .
$$

For $n$-component systems in which the mole fractions of all elements are equivalent, the fraction of element $i$ is given by

$$
y_{i}=\frac{1}{n} .
$$

When eq. (10) is applied, the parameters in eq. (9) become

$$
\begin{aligned}
& \sum_{i} \sum_{l} y_{i}^{l+1} L_{i, \mathrm{Va}}^{(l)}=\overline{L_{i, \mathrm{Va}}^{(0)}}, \\
& \sum_{i, j} \sum_{l}(1+l) y_{i} y_{j}\left(y_{i}-y_{j}\right)^{l} L_{i, j}^{(l)}=\frac{n-1}{2 n} \overline{L_{i, j}^{(0)}}, \\
& \sum_{i, j} y_{i}^{2} y_{j}{ }^{0} L_{i, j, \mathrm{Va}}=\frac{n-1}{2 n^{2}} \overline{{ }^{0} L_{i, j, \mathrm{Va}}}, \\
& \sum_{i, j} y_{i} y_{j}^{21} L_{i, j, \mathrm{Va}}=\frac{n-1}{2 n^{2}} \overline{{ }^{1}} \overline{L_{i, j, \mathrm{Va}}},
\end{aligned}
$$

where $\overline{L_{i, \text { Va }}^{(0)}}, \overline{L_{i, j}^{(0)}}, \overline{{ }^{0} L_{i, j, \mathrm{Va}}}$, and $\overline{{ }^{1} L_{i, j, \mathrm{Va}}}$ are average values of these parameters in binary and ternary systems. Using eq. (11) the vacancy fraction is

$$
y_{\mathrm{Va}}=\exp \left[-\frac{+\frac{n-1}{2 n^{2}}\left(\overline{{ }^{0} L_{i, j, \mathrm{Va}}}+\overline{{ }^{\mathrm{Va}}}+\overline{L_{i, j, \mathrm{Va}}}\right)}{R T}\right] .
$$

Assuming that the average values of the binding energy between $i$ and $\mathrm{Va}$ in matrix $j$ and that between $j$ and $\mathrm{Va}$ in matrix $i$ are roughly the same, eq. (12) becomes

$$
y_{\mathrm{Va}}=\exp \left[-\frac{G_{\mathrm{m}}^{\mathrm{Va}}+\overline{L_{i, \mathrm{Va}}^{(0)}}-\frac{n-1}{2 n} \overline{L_{i, j}}+\frac{n-1}{n^{2}} \overline{L_{i, j, \mathrm{Va}}}}{R T}\right] .
$$




\section{Results and Discussion}

4.1 Effect of the binary interactions and the solutevacancy pair formation on the vacancy fraction

To examine the effect of the $i-j \quad(i, j \neq \mathrm{Va})$ binary interactions and the solute-vacancy pair formation on the vacancy fraction, the ratio is defined as

$$
\frac{y_{\mathrm{Va}}}{{ }^{0} y_{\mathrm{Va}}}=\exp \left[-\frac{-\frac{n-1 \overline{2 n} L_{i, j}^{(0)}}{2 n}+\frac{n-1}{n^{2}} \overline{L_{i, j, \mathrm{Va}}}}{R T}\right],
$$

where ${ }^{0} y_{\mathrm{Va}}$ is the vacancy fraction in an ideal solution where $\overline{L_{i, j}^{(0)}}=\overline{L_{i, j, \mathrm{Va}}}=0$ in eq. (13). For the quinary system $(n=$ $5)$, the ratios of the vacancy fractions are plotted as a function of temperature in Fig. 1(a), where $\overline{L_{i, j}^{(0)}} \neq 0$ and $\overline{L_{i, j, \mathrm{Va}}}=0$, and in Fig. 1(b), where $\overline{L_{i, j}^{(0)}}=0$ and $\overline{L_{i, j, \mathrm{Va}}} \neq 0$. The values of the parameters used in the calculations are listed in the figures. The negative values of the parameters indicate attractive interaction between elements, whereas positive values indicate repulsive interaction. With the repulsive interaction between elements $i$ and $j$, the vacancy fraction increases because vacancies are introduced to avoid $i-j$ formation, whereas it decreases when the interaction is attractive. As temperature increases, the ratio converges to unity. The opposite tendency can be found for the $i-\mathrm{Va}$ binding energy, as presented in Fig. 1(a), where more vacancies form for the attractive interaction.

\subsection{Vacancy formation in Cantor alloy}

Cantor alloy consists of $\mathrm{Co}, \mathrm{Cr}, \mathrm{Fe}, \mathrm{Mn}$, and $\mathrm{Ni}$ and is an FCC solid solution. ${ }^{17)}$ The vacancy formation enthalpies in the five unary subsystems $\left(\overline{L_{i, \mathrm{Va}}^{(0)}}\right)$ were taken from the literature $^{18-34)}$ and are summarized in Table 1 . In the present work, the average values, excluding that for $\mathrm{Mn}$, are used in the following calculations. For the vacancy formation
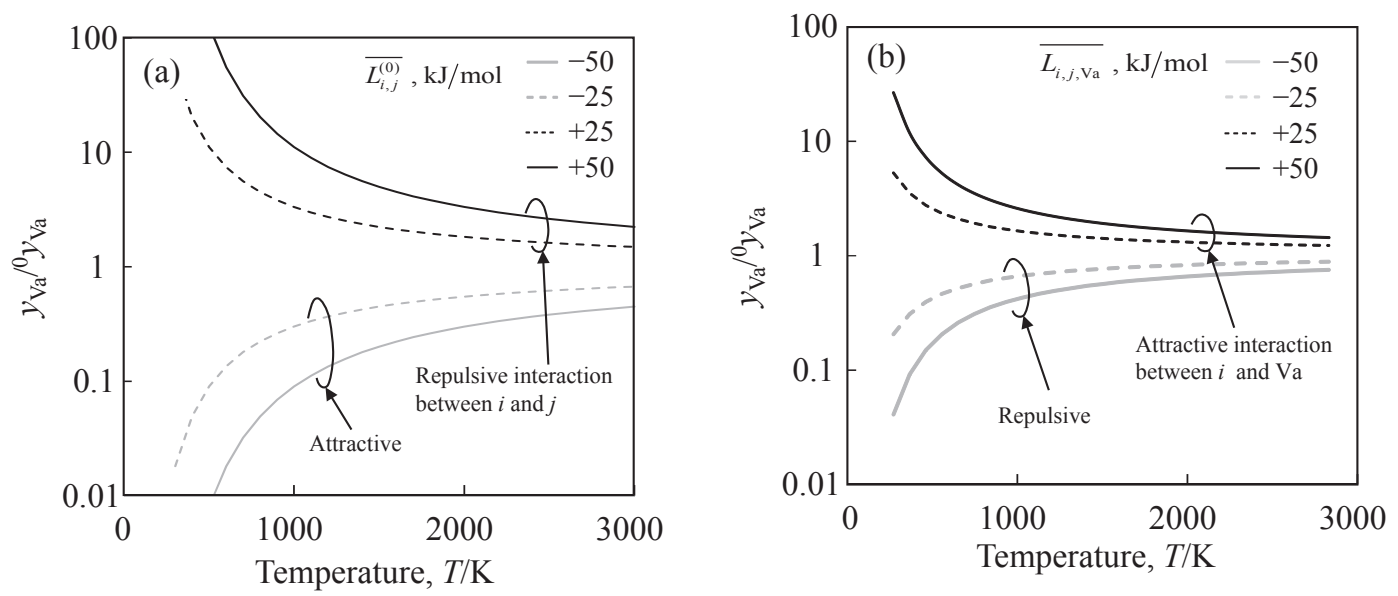

Fig. 1 Effect of (a) the $i$-Va binding energy and (b) the binary parameter on the vacancy fraction as a function of temperature in the alloys of $n=5$.

Table 1 Experimentally measured vacancy formation enthalpy in pure elements and in HEAs ${ }^{18-31)}$ (HEA(Cal.): estimated from ab initio calculations $;{ }^{32-34)} *$ average values; ${ }^{+}$values adopted in the present calculations).

\begin{tabular}{|c|c|c|c|c|c|}
\hline Element & 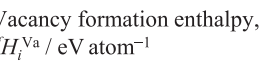 & Reference & Element & $\begin{array}{l}\text { Vacancy formation enthalpy, } \\
{ }^{f} H_{i} \mathrm{Va} / \mathrm{eV}^{-10 \mathrm{atom}^{-1}}\end{array}$ & Reference \\
\hline \multirow[t]{5}{*}{$\mathrm{Co}(\mathrm{FCC})$} & 1.34 & 18) & $\mathrm{Ni}$ & 1.54 & 26) \\
\hline & 1.91 & 19) & & 1.55 & 18) \\
\hline & 1.25 & 20) & & 1.65 & 27) \\
\hline & $1.5^{*,+}$ & & & 1.63 & 28) \\
\hline & & & & 1.74 & 29) \\
\hline \multirow[t]{3}{*}{$\mathrm{Cr}(\mathrm{BCC})$} & 2.27 & 21) & & 1.72 & 30) \\
\hline & 2.0 & 22) & & 1.55 & 31) \\
\hline & $2.1^{*,+}$ & & & $1.6^{*,+}$ & \\
\hline \multirow[t]{5}{*}{$\mathrm{Fe}(\mathrm{FCC})$} & 1.40 & 18) & HEA & $1.72^{+}$ & 25) \\
\hline & 1.5 & 23) & & & \\
\hline & 1.7 & 24) & HEA(Cal.) & $1.58-1.89$ & 32) \\
\hline & $1.5^{*,+}$ & & & (CoCrFeNi) & \\
\hline & & & & $1.59-2.35$ & 33) \\
\hline \multirow[t]{3}{*}{$\mathrm{Mn}(\mathrm{BCC})$} & $1.51^{+}$ & 25) & & $(\mathrm{CrFeMnNi})$ & \\
\hline & & & & $1.55-2.25$ & 34) \\
\hline & & & & (CoCrFeNi) & \\
\hline
\end{tabular}


Table 2 Assessed Redlich-Kister parameters $\left(\mathrm{J} \mathrm{mol}^{-1}\right)$ used in the present work: $\mathrm{Co}-\mathrm{Cr},{ }^{35)} \mathrm{Co}-\mathrm{Fe},{ }^{36)} \mathrm{Co}-\mathrm{Mn},{ }^{37)} \mathrm{Co}-\mathrm{Ni},{ }^{38)} \mathrm{Cr}-\mathrm{Fe},{ }^{39,40)} \mathrm{Cr}-$ $\mathrm{Mn},{ }^{41)} \mathrm{Cr}-\mathrm{Ni},{ }^{42)} \mathrm{Fe}-\mathrm{Mn},{ }^{43)} \mathrm{Fe}-\mathrm{Ni},{ }^{44)}$ and $\mathrm{Mn}-\mathrm{Ni} .{ }^{45)}$

\begin{tabular}{ll}
\hline$L_{\mathrm{Co}, \mathrm{Cr}}^{(0)}=-24052.09+8.1884 T$ & $L_{\mathrm{Cr}, \mathrm{Ni}}^{(0)}=+8030-12.8801 T$ \\
$L_{\mathrm{Co}, \mathrm{Cr}}^{(1)}=5331.8252-6.9059 T$ & $L_{\mathrm{Cr}, \mathrm{Ni}}^{(1)}=+33080-16.0362 * T$ \\
$L_{\mathrm{Co}, \mathrm{Fe}}^{(0)}=-8968.75$ & $L_{\mathrm{Fe}, \mathrm{Mn}}^{(0)}=-13107.0+13.8608 T+0.9523 T \ln T$ \\
$L_{\mathrm{C}, \mathrm{Fe}}^{(2)}=+3528.8$ & \\
$L_{\mathrm{Co}, \mathrm{Mn}}^{(0)}=-23756$ & $L_{\mathrm{F}, \mathrm{Ni}}^{(0)}=-12054.2532 \times 10^{-3} T^{2}+3.2854 \times 10^{-6} T^{3}$ \\
$L_{\mathrm{C}, \mathrm{Mn}}^{(1)}=-2343$ & $L_{\mathrm{Fe}, \mathrm{Ni}}^{(1)}=+11082.1315-4.4507 T$ \\
$L_{\mathrm{Co}, \mathrm{Ni}}^{(0)}=-800+1.2629 T$ & $L_{\mathrm{Fe}, \mathrm{Ni}}^{(2)}=-725.805174$ \\
$L_{\mathrm{Cr}, \mathrm{Fe}}^{(0)}=+10833-7.477 T$ & $L_{\mathrm{Mn}, \mathrm{Ni}}^{(0)}=-27996.5-1.2275 T$ \\
$L_{\mathrm{Cr}, \mathrm{Fe}}^{(1)}=+1410$ & $L_{\mathrm{Mn}, \mathrm{Ni}}^{(1)}=+19266.4-12.2853 T$ \\
$L_{\mathrm{Cr}, \mathrm{Mn}}^{(0)}=-19088+17.5423 T$ & \\
\hline
\end{tabular}



Fig. 2 Mole fraction of vacancy in pure elements and in the HEA. The obtained vacancy formation enthalpy is $1.7 \mathrm{eV}$ atom $^{-1}$ in this work.

entropy, due to lack of experimental data, it was assumed as ${ }^{f} S_{i}^{\mathrm{Va}}=+1.5 R T .{ }^{14)}$ In this quinary system, all 10 binary subsystems have been thermodynamically assessed based on the CALPHAD method. The R-K parameters were taken from the literature ${ }^{35-45)}$ and are listed in Table 2.

The equilibrium vacancy fractions were calculated on a thermodynamic calculation software package, PANDAT. ${ }^{46)}$ The calculated vacancy fraction is presented in Fig. 2. The formation enthalpy of vacancies in the HEA (Cantor alloy) derived from this Arrhenius plot is approximately $1.7 \mathrm{eV}$, in good agreement with the value of $1.72 \mathrm{eV}$ obtained from positron annihilation measurements by Sugita et al. ${ }^{25)}$ The average value of the vacancy formation enthalpy in pure elements (Co, $1.5 \mathrm{eV}$; Cr, $2.1 \mathrm{eV}$; Fe, $1.5 \mathrm{eV}$; Mn, $1.51 \mathrm{eV}$; Ni, $1.6 \mathrm{eV}$ ) is approximately $1.6 \mathrm{eV}$. The difference between this value and $1.7 \mathrm{eV}$ obtained in Fig. 2 can be explained by the effect of the binary interactions between elements $\left(\overline{L_{i, j}^{(0)}}\right)$. The excess Gibbs energy, $G^{\text {Excess }}$, is given by the $\mathrm{R}-\mathrm{K}$ polynomial for the equiatomic $n$-component system as

$$
G^{\text {Excess }}=\frac{1}{n^{2}} \sum_{i, j} L_{i, j}^{(0)}
$$

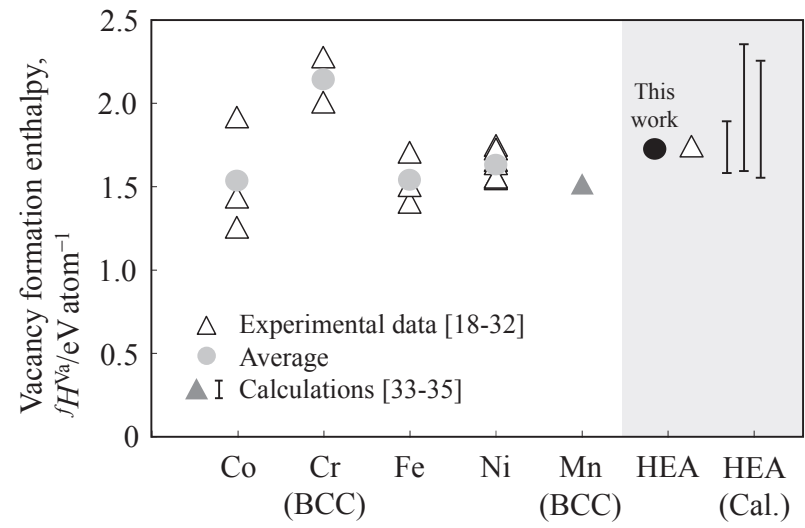

Fig. 3 Vacancy formation enthalpies in pure elements and in HEAs with the FCC structure, except for $\mathrm{Cr}$ and $\mathrm{Mn}$, which are BCC-structured. The average values of the experimental data were used in the present calculations.

Using the parameters listed in Table 2, the mixing enthalpy in the Cantor alloy is determined to be approximately $-2 \mathrm{~kJ} \mathrm{~mol}^{-1}$ at $1000 \mathrm{~K}$. The vacancy formation enthalpy increases by approximately $0.07 \mathrm{eV}$ due to the contribution from the binary interaction parameters. With this effect, the total vacancy formation enthalpy, $1.7 \mathrm{eV}$, was obtained in Fig. 2. Although in the above discussion the effect of vacancy-solute pair formations was not included, it is suggested that the effect of the pair formations might be less important in this HEA because the result in the present calculation agrees well with the experimental value of $1.72 \mathrm{eV}$. Even though the vacancy formation enthalpy in the pure elements obtained from experimental measurements and theoretical calculations can have uncertainty, as presented in Fig. 3, the HEA is within the same range.

As the vacancy formation enthalpy measured experimentally can be explained by the two contributions in the present model, which are vacancy formation enthalpy in pure elements and the interaction parameters, it can be concluded that the configurational effects to the sluggish diffusion cannot be significant in the vacancy formation enthalpy. 


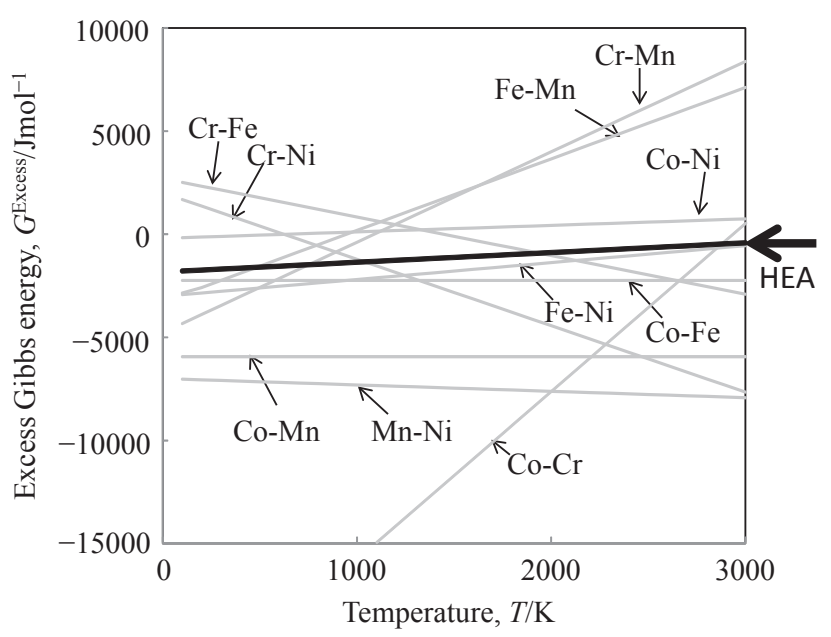

Fig. 4 Mixing enthalpy in the binary FCC solid solutions at the equiatomic composition and in the HEA as a function of temperature. The R-K parameters are listed in Table 2.

\subsection{Effect of mixing on the formation of HEAs}

The temperature dependency of the excess Gibbs energy in the binary subsystems and the Cantor alloy at the equiatomic composition were calculated using the parameters in Table 2 and are presented in Fig. 4. For these binary alloys, the excess Gibbs energy varies widely in the range from $-15,000$ to $+10,000 \mathrm{~J} \mathrm{~mol}^{-1}$. On the contrary, the large variation in the excess Gibbs energy of the binary systems was averaged; consequently, the excess Gibbs energy of the HEA became approximately $-2000 \mathrm{~J} \mathrm{~mol}^{-1}$. This result suggests that the variations in lower-order systems such as binary systems can disappear in the HEAs because of the mixing of multiple elements. According to Yang and Zhang, ${ }^{47)}$ solid-solution formation ability can be predicted based on a parameter $\Omega$, which is defined as

$$
\Omega=\frac{T_{\mathrm{m}} \Delta S_{\mathrm{mix}}}{\left|\Delta H_{\mathrm{mix}}\right|}
$$

where $T_{\mathrm{m}}, \Delta S_{\mathrm{mix}}$, and $\Delta H_{\mathrm{mix}}$ are the melting temperature, the entropy of mixing, and the enthalpy of mixing, respectively. The solid solutions can form when the lattice misfit is small and $\Omega$ is greater than unity. For the equiatomic alloys, when average values for $T_{\mathrm{m}}$ and $L_{i, j}^{(0)}$ are used, eq. (16) becomes approximately $\Omega \simeq 4 R \overline{T_{\mathrm{m}}} / \overline{L_{i, j}^{(0)}}$ for $n=4 \sim 6$. Compared with the variation in the average $T_{\mathrm{m}}$, which is likely in the range from 1000 to $3000 \mathrm{~K}$ for most of the equiatomic HEAs, $\left|L_{i, j}^{(0)}\right|$ can vary wider from 0 to $10^{4} \mathrm{~J} \mathrm{~mol}^{-1}$. Thus, it is a major factor determining $\Omega$. With the mixing of multiple elements, $\overline{L_{i, j}^{(0)}}$ can be closer to zero (the ideal solution), as evident in Fig. 4, and make the solution-phase stable. This fact might suggest that not only the mixing Gibbs energy but also other macroscopic properties can be averaged for HEAs because of the mixing of multiple elements.

Another important factor would be the lattice stability ${ }^{10)}$ to predict the formation of concentrated solid-solution phases. Recently, Takeuchi et al. ${ }^{48)}$ predicted stable ranges for an HCP-based HEA using a thermodynamic database. As in the CALPHAD method, the Unary ${ }^{49,50)}$ and various databases are available for discussing the lattice stability; this topic will be addressed in our future work.

\section{Conclusions}

In the present work, the thermodynamic description of the vacancy and the vacancy complex in binary alloys was expanded to HEAs within the framework of the CALPHAD method and was applied to estimate the vacancy fraction and the formation enthalpy in Cantor alloy. The following results were obtained.

(1) Using the average vacancy formation enthalpy of pure elements and the Redlich-Kister parameters, the vacancy fraction was described for multicomponent alloys. The estimated vacancy formation enthalpy in Cantor alloy was $1.7 \mathrm{eV}$ and was in good agreement with the experimental data obtained from the positron annihilation technique, $1.72 \mathrm{eV}$. This agreement suggests that, according to the vacancy formation enthalpy, the contribution of configurational effects to the sluggish diffusion cannot be significant.

(2) The variations in lower-order systems such as the binaries can disappear in the HEAs because of the mixing of multiple elements. Consequently, HEAs were close to the ideal solution.

\section{Acknowledgments}

This work was supported by the Grant-in-Aid for Scientific Research on Innovative Area, "High Entropy Alloys" (No. 18H05454).

\section{REFERENCES}

1) K.-Y. Tsai, M.-H. Tsai and J.-W. Yeh: Acta Mater. 61 (2013) 48874897.

2) M.-H. Tsai and J.-W. Yeh: Mater. Res. Lett. 2 (2014) 107-123.

3) J.-W. Yeh, S.-K. Chen, S.-J. Lin, J.-Y. Gan, T.-S. Chin, T.-T. Shun, C.-H. Tsau and S.-Y. Chang: Adv. Eng. Mater. 6 (2004) 299-303.

4) C.-J. Tong, Y.-L. Chen, S.-K. Chen, J.-W. Yeh, T.-T. Shun, C.-H. Tsau, S.-J. Lin and S.-Y. Chang: Metall. Mater. Trans. A 36 (2005) 881-893.

5) C.G. Schon, M.A. Tunes, R. Arroyave and J. Agren: Calphad 68 (2020) 101713.

6) J. Dabrowa, M. Zajusz, W. Kucza, G. Cieslak, K. Berent, T. Czeppe, T. Kulik and M. Danielewski: J. Alloy. Compd. 783 (2019) 193-207.

7) W. Kucza, J. Dabrowa, G. Cieslak, K. Berent, T. Kulik and M. Danielewski: J. Alloy. Compd. 731 (2018) 920-928.

8) Q. Li, W. Chen, J. Zhong, L. Zhang, Q. Chen and Z.-K. Liu: Metals 8 (2018) 16

9) A.D. Franklin: Point Defects in Solids, ed. by J.H. Crawford, Jr. and L.M. Slifkin, (Plenum Press, New York, 1972).

10) M. Hillert: Phase Equilibria, Phase Diagrams and Phase Transformations, (Cambridge University Press, Cambridge, 1998) pp. 428432.

11) S.-L. Shang, B.-C. Zhou, W.Y. Wang, A.J. Ross, X.L. Liu, Y.-J. Hu, H.-Z. Fang, Y. Wang and Z.-K. Liu: Acta Mater. 109 (2016) 128-141.

12) P. Franke: J. Phase Equil. Diff. 35 (2014) 780-787.

13) J. Ågren and M. Hillert: Calphad 67 (2019) 101666.

14) T. Abe, K. Hashimoto and M. Shimono: Mater. Trans. 59 (2018) 580584.

15) T. Abe, M. Shimono, K. Hashimoto and C. Kocer: Calphad 63 (2018) 100-106.

16) W.M. Lomer: "Pont defects and diffusion in metals and alloys", Inst. Metals Monograph, (London, 1958) pp. 79-98.

17) B. Cantor, I.T.H. Chang, P. Knight and A.J.B. Vincent: Mater. Sci. Eng. 
A 375-377 (2004) 213-218.

18) H. Matter, J. Winter and W. Triftshäuser: Appl. Phys. 20 (1979) 135 140.

19) C.W. Schulte and J.L. Campbell: Appl. Phys. 19 (1979) 269-273.

20) R. Kamel and K.Z. Botros: Phys. Status Solidi 12 (1965) 399-404.

21) J.L. Campbell and C.W. Schulte: Appl. Phys. 19 (1979) 149-152.

22) G.D. Loper, L.C. Smedskjaer, M.K. Chason and R.W. Siegel: Positron Annihilation, ed. by P.C. Jain, R.M. Singru and K.P. Gopinathan, (World Scientific Publishing Co., Singapore, 1985).

23) K. Maier, H. Metz, D. Herlach and H.-E. Schaefer: J. Nucl. Mater. 6970 (1978) 589-592.

24) S.M. Kim and W.J.L. Buyers: J. Phys. F 8 (1978) L103-L108.

25) K. Sugita, N. Matsuoka, M. Mizuno and H. Araki: Scr. Mater. 176 (2020) 32-35.

26) K.G. Lynn, C.L. Snead, Jr. and J.J. Hurst: J. Phys. F 10 (1980) 1753 1761.

27) S. Nanao, K. Kuribayashi, S. Tanigawa and M. Doyama: J. Phys. F 7 (1977) 1403-1419.

28) M.J. Fluss, L.C. Smedskjaer, B. Chakraborty and M.K. Chason: J. Phys. F 13 (1983) 817-825.

29) J.L. Campbell, C.W. Shulte and J.A. Jackman: J. Phys. F 7 (1977) 1985-1991.

30) G. Dlubek, O. Brümmer and N. Meyendorf: Phys. Status Solidi A 39 (1977) K95-K99.

31) K. Maier, M. Peo, B. Saile, H.E. Schaefer and A. Seeger: Philos. Mag. A 40 (1979) 701-728.

32) W. Chen, X. Ding, Y. Feng, X. Liu, K. Liu, Z.P. Lu, D. Li, Y. Li, C.T.
Liu and Z.-Q. Chen: J. Mater. Sci. Technol. 34 (2018) 355-364.

33) C. Li, J. Yin, K. Odbadrakh, B.C. Sales, S.J. Zinkle, C. Malcolm Stocks and B.D. Wirth: J. Appl. Phys. 125 (2019) 155103

34) S. Zhao, T. Egami, G. Malcom Stocks and Y. Zhang: Phys. Rev. Mater. 2 (2018) 013602.

35) K. Oikawa, G.-W. Qin, T. Ikeshoji, R. Kainuma and K. Ishida: Acta Mater. 50 (2002) 2223-2232.

36) I. Ohnuma, H. Enoki, O. Ikeda, R. Kainuma, H. Ohtani, B. Sundman and K. Ishida: Acta Mater. 50 (2002) 379

37) W. Huang: Calphad 13 (1989) 231-242.

38) A. Fernandez-Guillermet, Z. Metallk. 78 (1987) 639-647.

39) B.-J. Lee: Calphad 17 (1993) 251-268.

40) J.-O. Andersson and B. Sundman: Calphad 11 (1987) 83-92.

41) B.-J. Lee: Metall. Trans. A 24A (1993) 1925.

42) P. Turchi, L. Kaufman and Z.-K. Liu: Calphad 30 (2006) 70-87.

43) V.T. Witusiewicz, F. Sommer and E.J. Mittemeijer: J. Phase Equil. Diff. 25 (2004) 346-354.

44) G. Cacciamani, A.T. Dinsdale, M. Palumbo and A. Pasturel: Intermetallics 18 (2010) 1148-1162.

45) C. Guo and Z. Du: Intermetallics 13 (2005) 525-534.

46) CompuTherm LLC Home page: http://www.computherm.com.

47) X. Yang and Y. Zhang: Mater. Chem. Phys. 132 (2012) 233-238.

48) A. Takeuchi, T. Wada and H. Kato: Mater. Trans. 60 (2019) 22672276.

49) Scientific Group Thermodata Europe, Unary database 5.0: http:// www.crct.polymtl.ca/.

50) A.T. Dinsdale: Calphad 15 (1991) 317-425. 